\title{
Advanced laser fistula ablation for middle transsphincteric fistula-in-ano
}

\author{
J. Pintor-Tortolero ${ }^{1}$ (D) . C. Garcia-Sanchez ${ }^{1}$ - M.-L. Reyes-Diaz ${ }^{1}$. I. Ramallo-Solis ${ }^{1} \cdot$ G. Anguiano-Diaz ${ }^{1}$ F. De la Portilla ${ }^{1}$
}

Received: 16 June 2021 / Accepted: 27 July 2021 / Published online: 5 October 2021

(c) Springer Nature Switzerland AG 2021

Keywords Complex-fistula-in-ano $\cdot$ Lasar-ablation $\cdot$ Fecal-incontinence $\cdot$ Sphincter-saving procedure

Anal fistula is one of the most frequent anorectal disorders. Although most fistulas are simple and can be easily resolved by fistulotomy or fistulectomy, some cases are complex and constitute a real challenge for the surgeon, as continence must be preserved while the suppurative process is eradicated.

Advanced laser fistula ablation (ALFA ${ }^{\mathrm{TM}}$; neoLaser, Caesarea, Israel) is a new sphincter-saving procedure that involves intermittent thermal ablation of the fistula tract. A radial emitting optical fiber is used for laser energy delivery to destroy the epithelium lining inside the fistula tract and to induce obliteration of the remaining tract via a shrinkage effect.

First studies reported promising outcomes with overall healing rates of $70-80 \%[1,2]$. However, most of them were retrospective case series of a limited number of patients. Most recent studies have showed poorer outcomes with overall healing rates of 33-45\% [3-5]. In the attached video, ALFA $^{\mathrm{TM}}$ is performed in a 42-year-old male with a middle transsphincteric right posterior perianal fistula diagnosed with 3D endoanal ultrasound. The ALFA TM was chosen as a minimally invasive, sphincter-saving procedure considering the transphincteric pathway of the fistula tract, the length of the fistula tract (shorter than $4 \mathrm{~cm}$ ) and the absence of undrained collections or cavities because of our personal experience of success in fistula with similar characteristics. Fistula tract catheterization was eased by sheathing the metal probe in a previously sectioned tube. Then, the metal probe was withdrawn and the laser fiber was introduced until the tip protruded through the internal fistula opening. Finally,

J. Pintor-Tortolero

josepintortortolero@gmail.com

1 Virgen del Rocío University Hospital, Av/Manuel Siurot $\mathrm{S} / \mathrm{N}, 41013$ Seville, Spain the aspiration tube was removed, and the laser system was activated.

Supplementary Information The online version contains supplementary material available at https://doi.org/10.1007/s10151-021-02502-y.

\section{Declarations}

Conflict of interest The authors declare that they have no conflict of interest.

Ethical approval All procedures performed in the study involving human participants were in accordance with the ethical standards of the Trust and with the 1964 Helsinki declaration and its later amendments or comparable ethical standards.

Informed consent Informed consent was obtained from all individual participants included in the study.

\section{References}

1. Wilhelm A (2011) A new technique for sphincter-preserving anal fistula repair using a novel radial emitting laser probe. Tech Coloproctol 15(4):445-449

2. Giamundo P, Esercizio L, Geraci M, Tibaldi L, Valente M (2015) Fistula-tract Laser Closure (FiLaCTM): long-term results and new operative strategies. Tech Coloproctol 19(8):449-453

3. Terzi MC, Agalar C, Habip S, Canda AE, Arslan NC, Obuz F (2018) Closing perianal fistulas using a laser: long-term results in 103 patients. Dis Colon Rectum 61(5):599-603

4. Lauretta A, Falco N, Stocco E, Bellomo R, Infantino A (2018) Anal fistula laser closure: the length of fistula is the Achilles' heel. Tech Coloproctol 22(12):933-939

5. Marref I, Spindler L, Aubert M, Lemarchand N, Fathallah N, Pommaret E et al (2019) The optimal indication for FiLaC® is high trans-sphincteric fistula-in-ano: a prospective cohort of 69 consecutive patients. Tech Coloproctol 23(9):893-897

Publisher's Note Springer Nature remains neutral with regard to jurisdictional claims in published maps and institutional affiliations. 